\title{
Performance test and typical fault analysis of electric emergency power supply vehicle
}

\author{
Chunhui $\mathrm{Gu}^{1 *}$, Jian Fang ${ }^{1}$, Zichong Zhang ${ }^{1}$ and Jianping Gong ${ }^{2}$ \\ ${ }^{1}$ Electric Power Test \&Research Institute, Guangzhou Power Supply Bureau of Guangdong Power Grid Co., Ltd, Guangzhou, \\ Guangdong, 510000, China \\ ${ }^{2}$ Safety Supervision Department, China Southern Power Grid Co., Ltd, Guangzhou, Guangdong, 510000, China
}

\begin{abstract}
In the emergency repair of electric power caused by sudden natural disasters, the reliability and stability of emergency power supply vehicles largely determine the speed and efficiency of restoring power supply. Based on the performance test and reliability study of 18 diesel-powered vehicles in Guangzhou Power Supply Company Limited, the typical defects of emergency power supply equipment and the causes of the faults are analyzed. It provides technical support for the technical standards and the maintenance guidance of emergency power supply equipment, and greatly improves the emergency capability of rapid power recovery under extreme natural disasters. It has improved the emergency response capability of rapid re-powering under extreme natural disasters, shortened the repair time, and significantly reduced the loss and impact of extreme natural disasters on the power system and the entire national economy.
\end{abstract}

\section{Introduction}

At present, there is no national standard and industry standard for emergency power supply vehicles used in power grid emergency repairs. China Southern Power Grid also lacks the detection ability of emergency equipment products[1-2]. The emergency power equipment manufacturers are numerous and mixed, the product quality is uneven and the threshold is very low. It is urgent to strengthen quality control of emergency power supply vehicles. The aim of this paper is to study the related technologies of emergency power generation equipment, and to improve the quality, operation and reliability of emergency power generation equipment by establishing technical standards, technical specifications and operational guidance of emergency equipments [3-4]. The emergency capability of power cut and repair under extreme natural disasters will be greatly improved, the repair time will be shortened, and the losses and impacts of extreme natural disasters on the power system and even on the national economy will be significantly reduced. It greatly improves the quality level and reliability of emergency power supply equipments[5].

In the process of emergency rescue, the reliability and stability of emergency power generation equipment have a great impact on the rapid recovery of power, such as the quality problems of emergency power generation equipment, which will bring great hidden dangers and adverse effects to the emergency repair work[6]. At present, there are no national standards and industry standards for emergency power supply vehicles used in power grid emergency repair, and China Southern Power
Grid also lacks the detection ability of emergency equipment products; moreover, there are many manufacturers of emergency power generation equipment, and the product quality is uneven and the threshold is low, so it is urgent to strengthen the quality control[7-8]. The purpose of this paper is to study the performance of typical emergency power generation equipment diesel electric emergency power generation vehicle. The research is expected to lay the foundation for the formulation of technical standards, technical specifications and operation and maintenance guidance of emergency power generation equipment, improve the management level of emergency power generation equipment, and enhance the operability and reliability of equipment.

\section{Samples}

This article studies the operation performance of 56 power emergency diesel generators in service in a power supply bureau. These power generators have been in use for 4 to 9 years with a rated output voltage of $230 \mathrm{~V}$ and a rated output power of 200,400 or $500 \mathrm{~kW}$. Before the test, no damage was found on the tested generator.

\section{Reference Standards and Performance Parameters}

This research work is carried out strictly in accordance with the requirements of China's national standard GB/T 20136-2006 "General Test Methods for Internal Combustion Engine Power Stations", industry standard

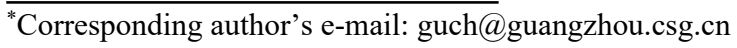


YD/T 502-2007 "Diesel Generator Set for Communication" and relevant technical agreements of a power supply bureau. The performance judgment is based on the technical agreement. When the technical agreement is lower than the national standard, industry standard or enterprise commitment, the higher requirements in the national/industry standard or enterprise commitment shall be taken as the performance judgment basis.

The performance and parameters studied include steady-state voltage deviation and steady-state frequency deviation, transient voltage deviation and transient frequency deviation, voltage and frequency recovery time, three-phase voltage imbalance, frequency drop, phase voltage sine wave distortion rate, insulation resistance and other non-electrical performance and parameters, as well as operation state parameter monitoring function, overload protection function, emergency stop function, continuous operation function, generator appearance and phase sequence arrangement.

\section{TEST ITEMS}

\subsection{Steady-state voltage and frequency deviation}

The research steps of this performance parameter are as follows: start and set the generator to operate stably under rated conditions, and reduce the load to no load after a period of time; Gradually load from no-load to
$25 \%, 50 \%, 75 \%, 100 \%$ of rated load, then reduce the load from $100 \%$ to no-load step by step according to this grade, and run for a period of time under each grade of load; Test the three-phase voltage, frequency and output power under various load levels. According to relevant technical requirements, the deviation between steadystate voltage and rated voltage shall be $\leq \pm 0.5 \%$, and the deviation between steady-state frequency and rated frequency shall be $\leq \pm 0.5 \%$.

Figure $1 \&$ Figure 2 show the time variation characteristics (steady-state) of three-phase voltage, frequency and output power under different load rates for a $500 \mathrm{~kW}$ diesel generator under inspection. In order to visually judge whether the steady-state voltage and steady-state frequency meet the requirements (the steadystate voltage deviation should be less than or equal to $0.5 \%$, and the steady-state frequency deviation should be less than or equal to $0.5 \%$ ), the upper and lower boundary lines of the steady-state voltage and steadystate frequency are respectively made in the figure and the upper and lower limit values are marked. It can be seen from Figure $1 \&$ Figure 2 that under no-load condition, the three-phase voltage basically changes within the allowable deviation range of steady-state voltage; the larger the load rate is, the more the threephase voltage decreases compared with the rated phase voltage, and the more it deviates from the lower limit of steady-state voltage, among which the decrease of Aphase voltage is the most obvious.

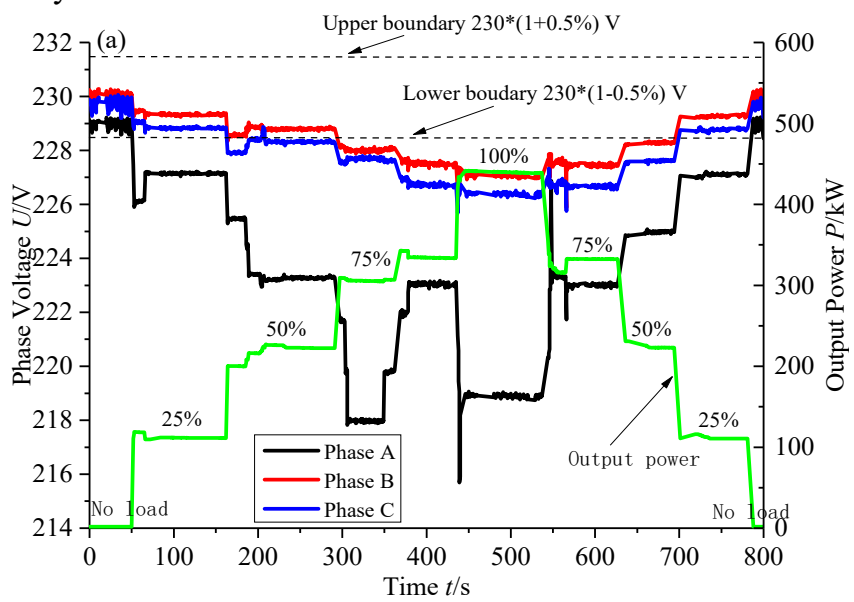

Figure 1. Time variation characteristics of output voltage and power of $500 \mathrm{~kW}$ power generator (steady-state)

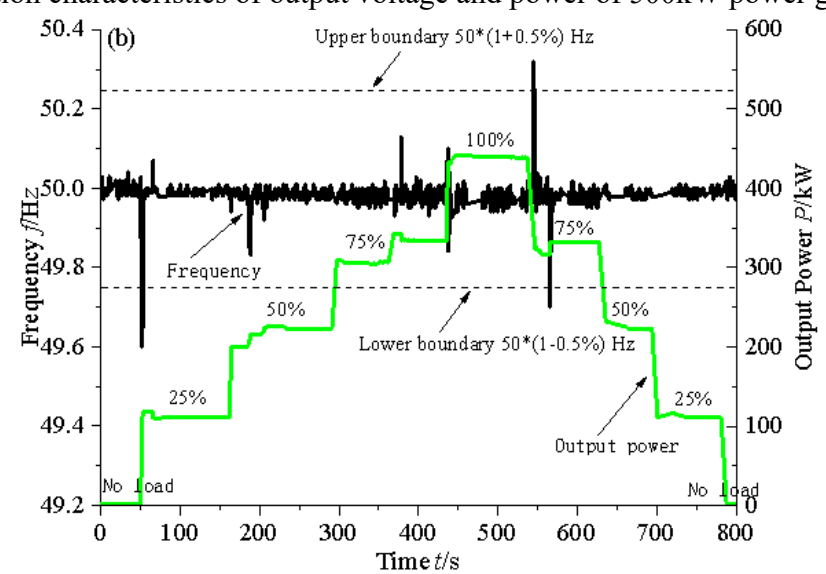

Figure 2. Time variation characteristics of output frequency and power of 500kW power generator (steady-state) 


\subsection{Transient voltage, frequency deviation and voltage and frequency recovery time}

The research steps of this performance parameter are as follows: start and set the generator to operate stably under rated conditions, and suddenly reduce to no load after a period of time; Sudden load increase to rated load, after stable operation, sudden load reduction to no load; Test the three-phase voltage, frequency and output power during sudden load increase and sudden load decrease. According to relevant technical requirements, transient voltage deviation should be $\leq \pm 15 \%$, transient frequency deviation should be $\leq \pm 7 \%$, voltage recovery time should be $\leq 1 \mathrm{~s}$, and frequency recovery time should be $\leq 3 \mathrm{~s}$.

Figure $3 \&$ Figure 4 show the time variation characteristics (transient) of three-phase voltage, frequency and output power when a $500 \mathrm{~kW}$ diesel generator under inspection suddenly reduces its load. It can be seen from figure 3 that when the load is suddenly reduced from the rated load to no load, the three-phase voltages all have "V" type abrupt changes, and their maximum drop values are about $8 \mathrm{~V}, 6 \mathrm{~V}$ and $4 \mathrm{~V}$ respectively, which are still within the allowable $\pm 15 \%$ transient voltage deviation range. As can be seen from figure 4, when the load suddenly decreases from the rated load to no load, the frequency also appears "V" type abrupt changes with the maximum decrease value of about $1.5 \mathrm{~Hz}$, which is still within the allowable $\pm 7 \%$ transient frequency deviation range. Similar studies show that when the load suddenly increases from no-load to rated load, the maximum drop of three-phase voltage exceeds the allowable range of $\pm 15 \%$ transient voltage deviation. The maximum frequency drop is still within the allowable $\pm 7 \%$ transient frequency deviation.

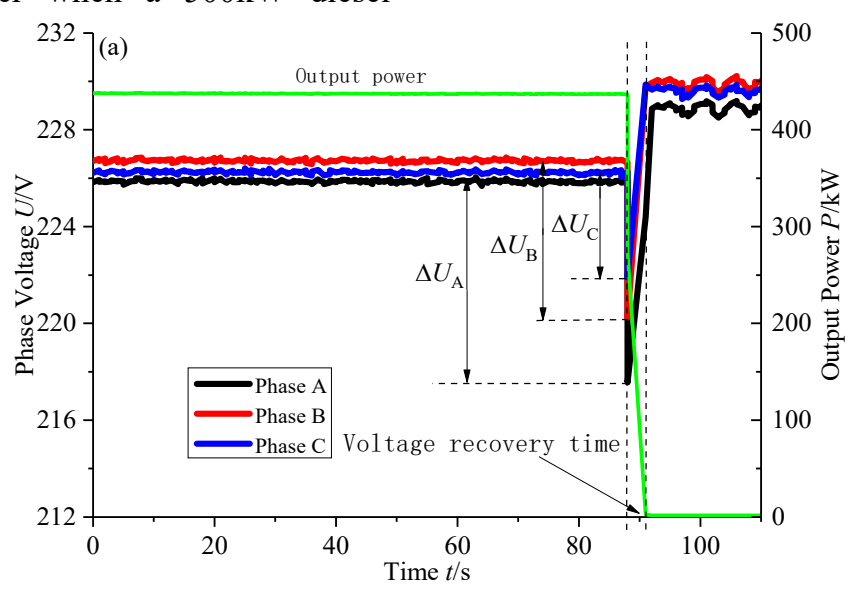

Fig. 3 Time varying characteristics of three phase voltage and output power during sudden load reduction (transient)

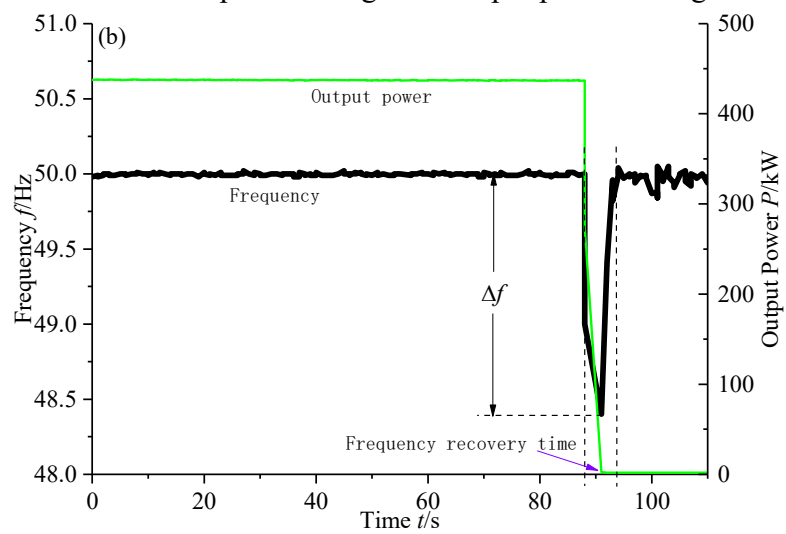

Fig. 4 Time varying characteristics of three phase frequency and output power during sudden load reduction (transient)

\subsection{Three-phase voltage imbalance}

The research steps of this performance parameter are as follows: start and set The research steps of this performance parameter are as follows: start and set the generator to operate stably under rated conditions, reduce the load to no-load after a period of time, and test the voltage imbalance degree when no-load occurs. According to the relevant technical requirements, the voltage unbalance shall be $\leq 1 \%$ when no load is applied. the generator to operate stably under rated conditions, reduce the load to no-load after a period of time, and test the voltage imbalance degree when no-load occurs. According to the relevant technical requirements, the voltage unbalance shall be $\leq 1 \%$ when no load is applied. Figure 5 shows the time variation characteristics of the three-phase voltage when a tested $500 \mathrm{~kW}$ diesel generator vehicle is running stably at no load. the tester shows that its three-phase voltage imbalance is $0.26 \%$, which meets the requirement that the voltage imbalance should be $\leq 1 \%$ at no load. 


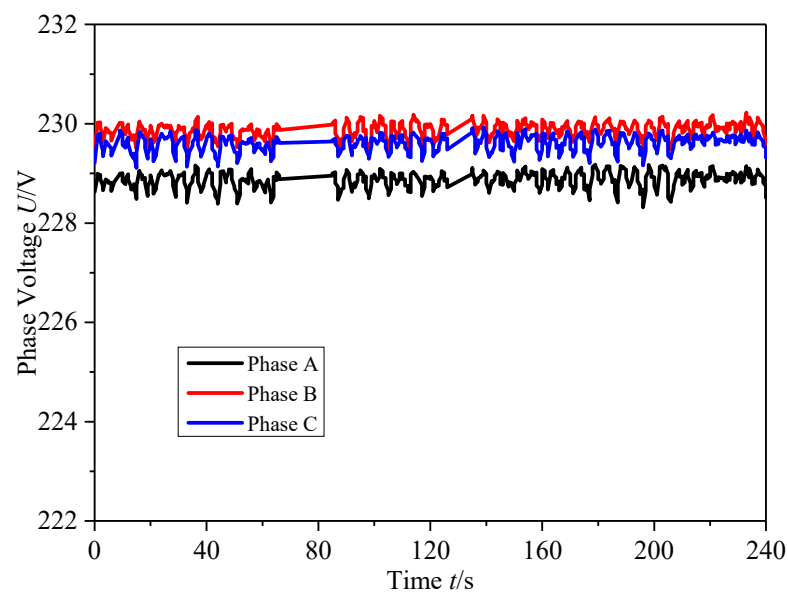

Fig.5 Time variation characteristics of three-phase voltage for $500 \mathrm{~kW}$ diesel generator under no-load stable operation.

\subsection{Phase voltage sine wave distortion rate}

The research steps of this performance parameter are as follows: the generator is in a cold state or a hot state, and the generator is started and adjusted to operate stably under the rated working condition; After a period of time, reduce the load to no load and adjust the frequency to the rated value to test the three-phase voltage and its sine wave distortion rate. According to relevant technical requirements, the sine wave distortion rate of three-phase voltage shall be $\leq 3 \%$ when no load is applied and $\leq 10 \%$ when full load is applied.

Figure 6 shows the time variation characteristics of the three-phase voltage and its sine wave distortion rate when a $500 \mathrm{~kW}$ diesel generator under inspection is unloaded. It can be seen from the figure that the sine wave distortion rate of the three-phase voltage fluctuates up and down at 1.3 when no load is applied, and the distortion rate of phase $\mathrm{B}$ is the smallest and that of phase $\mathrm{C}$ is the largest, but all meet the requirement that the sine wave distortion rate of the voltage is $\leq 3 \%$ when no load is applied.

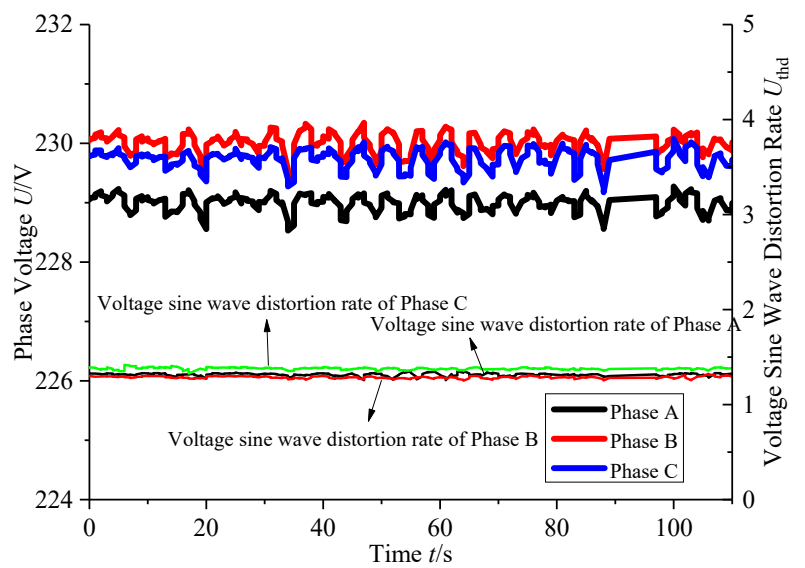

Fig.6 Time variation characteristics of three-phase voltage and sine wave distortion rate of $500 \mathrm{~kW}$ diesel generator under no-load condition

\section{Continuous operation}

The research steps of this performance parameter are as follows: start and set the generator to run stably under the rated working condition, making it run continuously for 60min under full load; During the operation, the generator will not stop without warning. After the operation, the generator unit will be checked for oil leakage, water leakage and other abnormal phenomena. The diesel generator is considered to have normal continuous operation capability.

Of the 56 diesel generators tested, 10 failed in continuous operation; One of them can run continuously for $60 \mathrm{~min}$, but after the operation, the unit was found to have oil leakage; The other 9 power generators will stop when they are running for less than $60 \mathrm{~min}$. The continuous operation time of most unqualified diesel generators is between $20 \mathrm{~min}$ and $30 \mathrm{~min}$, except that the continuous operation time of 2 generators is less than $15 \mathrm{~min}$. In addition, the detection found that the reason why most power generators stop is that the unit cooling water temperature is too high, which leads to alarm shutdown. It can be seen that after a period of service, the continuous operation capability of some power generators cannot meet the technical requirements, and the most likely reason is the reduction of heat dissipation capability.

\section{Conclusions}

According to China's national standard GB/T 201362006 "General Test Methods for Internal Combustion 
Engine Power Stations", industry standard YD/T 5022007 "Diesel Generator Set for Communication" and relevant technical regulations, this article systematically studies various performance parameters of 56 electric emergency diesel generators after serving for a certain period of time.

a) After a certain period of service, the steady-state frequency deviation, voltage imbalance, frequency drop, insulation resistance, overload protection, emergency stop function and monitoring function have not occurred or only a small number of power generators have failed, which indicates that the above performance and function are stable.

b) After a certain period of service, nearly $40 \%$ of the power generators have excessive steady-state or transient voltage deviation, and nearly $70 \%$ of the power generators have excessive transient frequency deviation. The deterioration of output voltage and frequency of power generators is obvious, which seriously affects the quality of emergency power supply. The maintenance of diesel power generators should attach great importance to these quality indicators and shorten the test cycle appropriately.

c) After a certain period of service, $25 \%$ of the power generators are not qualified for continuous operation, and the operation time with rated load is less than $60 \mathrm{~min}$. This seriously affects the reliability of emergency power supply and brings hidden dangers to emergency power supply. The maintenance of diesel power generators should pay more attention to full load operation capability to ensure normal continuous operation capability.

\section{Acknowledgments}

The project was funded by the Key Laboratory of Medium-voltage and Low-voltage Electric Equipment Inspection and Testing of China Southern Power Grid, China.

\section{References}

1. Zhang, Z.C., Qin, Y., Gu, C.H. and Xu, Z.B., (2018) Research on operating performances of $500 \mathrm{kVA}$ flywheel energy storage UPS power supply vehicle. Movable Power Station\&Vehicle, vol. 3, pp. 25-29.

2. Zhang, Z.C., Qin, Y., Gu, C.H. and Xu, Z.B. (2019) Research on operating performances of $300 \mathrm{kVA}$ zero switching time of UPS emergency power supply vehicle. Electrical Technology, vol. 1, pp. 710

3. Qin, Y., Gu, C.H., Zhang, Z.C. and Xu, Z.B. (2019) Research on performance state of $500 \mathrm{~kW}$ diesel electric emergency generator vehicle,"Electrical Age, vol. 4, pp. 55-58.

4. GB/T 20136-2006. General Test Methods for Internal Combustion Engine Power Stations [S]. Lanzhou Power Vehicle Research Institute, China Electrical Equipment Industry Association. 2006.
5. YD/T 502-2007. (2007) Diesel Generator Set for Communication [S].

6. Analysis of common problems in customer electrical equipment power quality[M]. China Electric Power Press, 2013.

7. Wang, Y. (2015) Research on Management System and Capability Evaluation of Power System Sudden Disaster Emergency Project [D]. North China Electric Power University.

8. Wang, Z.K., Sun, L., Lin, Z.Z. (2018) Optimal Allocation of Emergency Power Sources Considering Uncertainties of Loads and Dispatching Time Periods[J]. Automation of Electric Power Systems. 42(2): 34-41. 